\title{
Theoretical Investigation of the Electronic Structure of the Strontium Mono-Sulfide Molecule SrS Using the ab initio Calculation Method
}

\author{
Hanan Hijazi ${ }^{1} \&$ Mahmoud Korek $^{1}$ \\ ${ }^{1}$ Faculty of Science, Beirut Arab University, Lebanon \\ Correspondence: Mahmoud Korek, Faculty of science, Beirut Arab University, P. O. Box 11-5020, Beirut \\ Lebanon. E-mail: mahmoud.korek@bau.edu.lb, fkorek@yahoo.com
}

Received: May 22, 2018

Accepted: May 30, 2018

Online Published: July 25, 2018

doi:10.5539/mas.v12n8p81

URL: https://doi.org/10.5539/mas.v12n8p81

\begin{abstract}
The ground state and 23 other low-lying singlet and triplet electronic states of the strontium mono-sulfide molecule $\mathrm{SrS}$, in the ${ }^{2 \mathrm{~s}^{+1}} \Lambda^{ \pm}$representation, have been examined by $a b$ initio calculations using the computational chemistry software MOLPRO and the graphical user interface GABEDIT. The potential energy curves, in terms of the internuclear distance R, resulted from the complete active space self-consistent field (CASSCF) and multi-reference doubly and singly configuration interaction (MRDSCI) with Davidson correction $(+\mathrm{Q})$ calculations. The permanent dipole moments $(\mu)$ and the spectroscopic constants $\left(T_{e}\right.$ : the electronic energy with respect to the ground state, $\omega_{\mathrm{e}}$ : the harmonic frequency, $\mathrm{R}_{\mathrm{e}}$ : the equilibrium internuclear distance, $\mathrm{B}_{\mathrm{e}}$ : the rotational constant, $\mathrm{D}_{\mathrm{e}}$ : the equilibrium dissociation energy) have been investigated. The results of this work are in good agreement with the results available in literature. Moreover, for the first time, it was possible to study 20 new singlet and triplet electronic states of SrS molecule.
\end{abstract}

Keywords: strontium mono-sulfide, computational chemistry, $a b$ initio calculation, potential energy curves, permanent dipole moment curves, spectroscopic constants

\section{Introduction}

In many areas of chemistry, the compound SrS, as all metal sulfides, is of great importance regarding the nature of the metal-sulfur bond. Corrosion processes, high temperature chemistry, and chemical vapor deposition are some examples of the significance of metal sulfide compounds (Halfen, Apponi, Thompsen, \& Ziurys, 2001) (Bradley, 1989). Metal sulfides also play a role in biochemistry (Janczyk \& Ziurys, 2006) where they are considered as sulfur-donating ligands in protein related reactions (Holm, Kennepohl \& Solomon, 1996) (Halfen, Apponi, Thompsen, \& Ziurys, 2001). Moreover, alkaline earth sulfide applications also exist in astrophysics (Takano, Yamamoto, \& Saito, 1989) (Janczyk \& Ziurys, 2006). Therefore, scientists are often interested in studying their properties.

Many alkaline-earth metal sulfides have been investigated experimentally and theoretically. However, studies conducted on the SrS molecule, unfortunately, remained few and constricted to only some low-lying electronic states (Marcano \& Barrow, 1970) (Huber \& Herzberg, 1979). For instance, a laser spectroscopy experiment was conducted, in 1988, on strontium sulfide, SrS, in order to obtain molecular constants, such as vibrational constants, rotational constants and bond lengths, with high accuracy and precision. The results were limited to 2 electronic states only, the ground state $\mathrm{X}^{1} \Sigma^{+}$and the first excited state $(2)^{1} \Sigma^{+}$(Pianalto, Brazier, Obrien, \& Bernath, 1988). Another experimental study, in 2001, allowed the recording of the bond length of SrS, for state $\mathrm{X}^{1} \Sigma^{+}$, using millimeter/submillimeter-wave direct absorption methods (Halfen, Apponi, Thompsen, \& Ziurys, 2001). Later, in 2010, experimental recordings were done on 4 isotopes of strontium mono-sulfide and the spectroscopic constants of the ground state $\mathrm{X}^{1} \Sigma^{+}$were obtained (Etchison \& Cooke, 2010). Theoretically, this molecule has been studied by Partridge et al. using ab initio calculations. The study resulted in spectroscopic constants computed by 5 different calculation techniques (CASSCF: complete active space self-consistent field, CCI: contracted configuration interaction, $\mathrm{CCI}(4 \mathrm{~s} 4 \mathrm{p})$ : $\mathrm{CCI}$ with core correlation, MRCI: multi-reference configuration interaction, MRCI+Core: MRCI with core correlation) for three low-lying SrS electronic states: $\mathrm{X}^{1} \Sigma^{+},(1)^{3} \Pi$, and (1) $\Pi$ (Partridge, Langhoff, \& Bauschlicher, 1988).

In the present work, the investigation of the ground state and several low-lying singlet and triplet electronic states of $\mathrm{SrS}$, in the ${ }^{2 s+1} \Lambda^{ \pm}$representation, is done using multi-reference configuration interaction (MRCI with 
Davidson correction) according to the $a b$ initio computational method. Accordingly, the potential energy curves (PECs) of 24 electronic states and the permanent dipole moment curves (DMCs) of 19 electronic states are presented. The corresponding spectroscopic constants, such as the electronic energy with respect to the ground state $\left(T_{e}\right)$, the harmonic frequency $\left(\omega_{e}\right)$, the internuclear distance at equilibrium $\left(\mathrm{R}_{\mathrm{e}}\right)$, the rotational constant $\left(\mathrm{B}_{\mathrm{e}}\right)$ and the dissociation energy $\left(D_{e}\right)$, are also computed for 19 electronic states. Out of the 24 low-lying electronic states that are demonstrated in the current work, 20 new electronic states are studied here for the first time.

\section{Computational Approach}

Taking advantage of the graphical user interface GABEDIT (Allouche, 2010), the computational chemistry program MOLPRO (Werner, Knowles, Knizia, Manby, \& Schütz, 2011) has been used in the current study to apply $a b$ initio techniques to the strontium mono-sulfide compound. Using the state averaged complete active space self-consistent field (CASSCF) approach, the low-lying singlet and triplet electronic states of the diatomic molecule SrS have been studied by the method of multi-reference doubly and singly configuration interaction (MRDSCI) with Davidson correction $(+\mathrm{Q})$. The strontium atom $\mathrm{Sr}$, in its neutral state with 38 electrons, is treated with the energy-consistent effective core potential ECP28MWB basis (Kaupp, Schleyer, Stoll \& Preuss, 1991), for $s, p$ and $d$ functions (6s, $6 p, 5 d) /[4 s, 4 p, 2 d]$, where 28 electrons are considered in the core and the remaining 10 electrons are valence. As for the neutral sulfur atom $S$, its 16 electrons are distributed into 10 core electrons and 6 valence electrons using the ECP10MWB basis set (Bergner, Dolg, Kuechle, Stoll \& Preuss, 1993) for $\mathrm{s}$ and $\mathrm{p}$ functions $(4 s, 5 p) /[2 s, 3 p]$. Both Wood-Boring (WB) effective core potential basis sets, ECP28MWB and ECP10MWB, represent a quasi-relativistic theoretical level of reference. Considering strontium mono-sulfide's 54 electrons, of which 38 electrons are for $\mathrm{Sr}$ and 16 electrons are for S, 38 electrons are made to belong to the core of the molecule (28 electrons from $\mathrm{Sr}$ and 10 electrons from $\mathrm{S}$ ) and 16 electrons (the 10 valence electrons of $\mathrm{Sr}$ and the 6 valence electrons of S) are kept outside this core. The wave functions of these 16 out-of-core electrons are specified using 19 molecular active orbitals formed on $4 s, 4 p, 4 d, 5 s, 5 p$ and $6 s$ of strontium and $3 s, 3 p$ and $4 s$ of sulfur. The later calculations are done by freezing 10 electrons in the $4 s$ and $4 p$ orbitals of $\mathrm{Sr}$ and in the $3 \mathrm{~s}$ orbital of S by keeping them doubly occupied, consequently leaving the explicit treatment to 6 valence electrons. As a result, the orbitals contained in the active space are $6 \sigma\left(\mathrm{Sr}: 5 s, 4 d_{0}, 5 p_{0}, 6 s\right.$; S: $\left.3 p_{0}, 4 s\right), 3 \pi\left(\mathrm{Sr}: 4 d_{ \pm 1}, 5 p_{ \pm 1} ; \mathrm{S}: 3 p_{ \pm 1}\right)$ and $1 \delta\left(\mathrm{Sr}: 4 d_{ \pm 2}\right)$ distributed into the irreducible representations $\mathrm{a}_{1}, \mathrm{~b}_{1}, \mathrm{~b}_{2}$ and $\mathrm{a}_{2}$ as $3 \mathrm{a}_{1}, 1 \mathrm{~b}_{1}, 1 \mathrm{~b}_{2}$ and $0 \mathrm{a}_{2}$, denoted by $[3,1,1,0]$ in the $\mathrm{C}_{2 \mathrm{v}}$ point group symmetry.

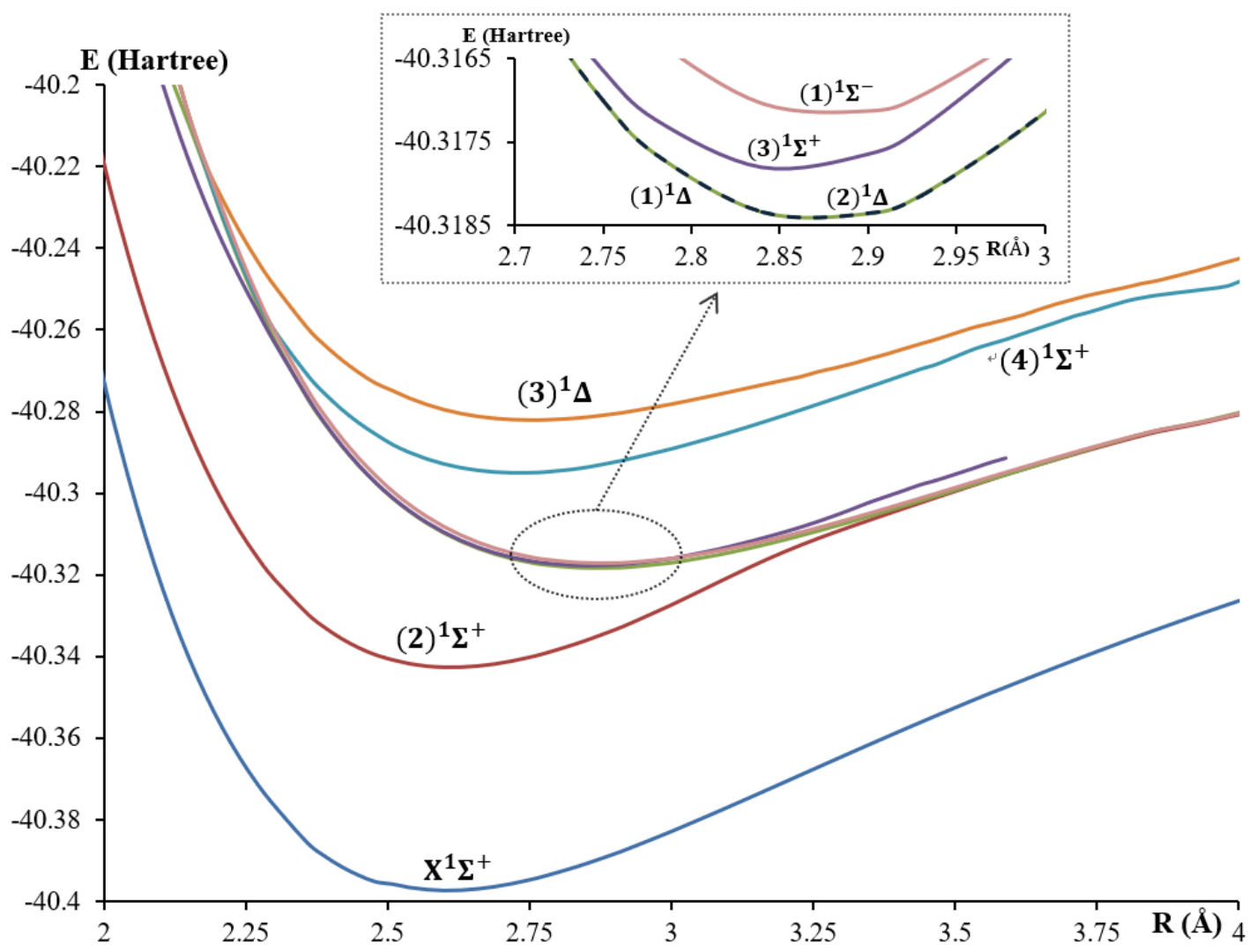

Figure 1. PECs of the singlet $\Sigma$ and $\Delta$ electronic states of $\mathrm{SrS}$ 


\section{Results and Discussion}

\subsection{Potential Energy Curves and Spectroscopic Constants}

In the range $2 \AA \leq R \leq 4.01 \AA$, the potential energy curves (PECs), as a function of R, for the 24 singlet and triplet low-lying electronic states of the $\mathrm{SrS}$ molecule, in the ${ }^{2 s+1} \Lambda^{ \pm}$representation, have been calculated and presented for 77 internuclear distances (Figs. 1-5).

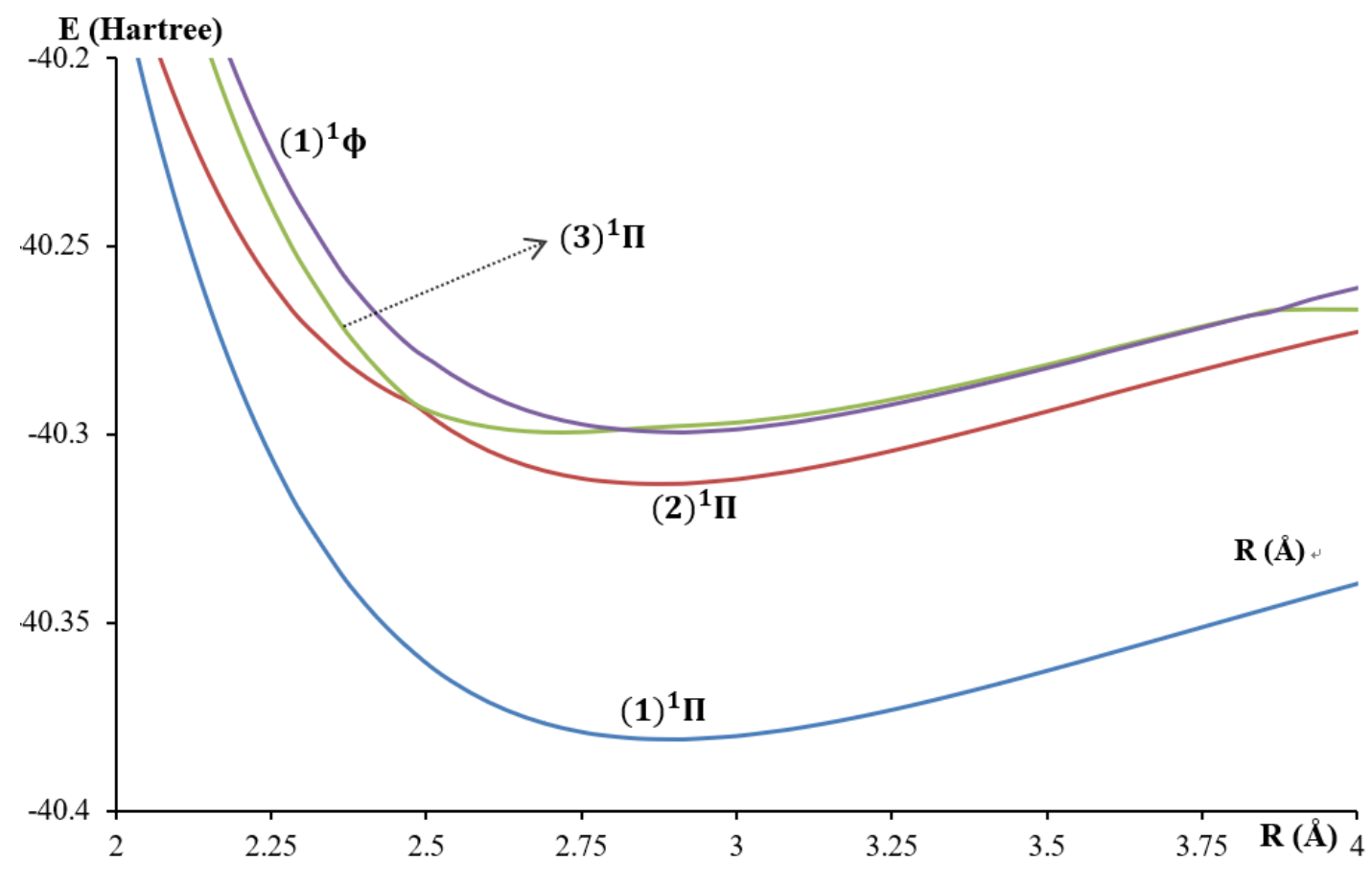

Figure 2. PECs of the singlet $\Pi$ and $\Phi$ electronic states of $\mathrm{SrS}$

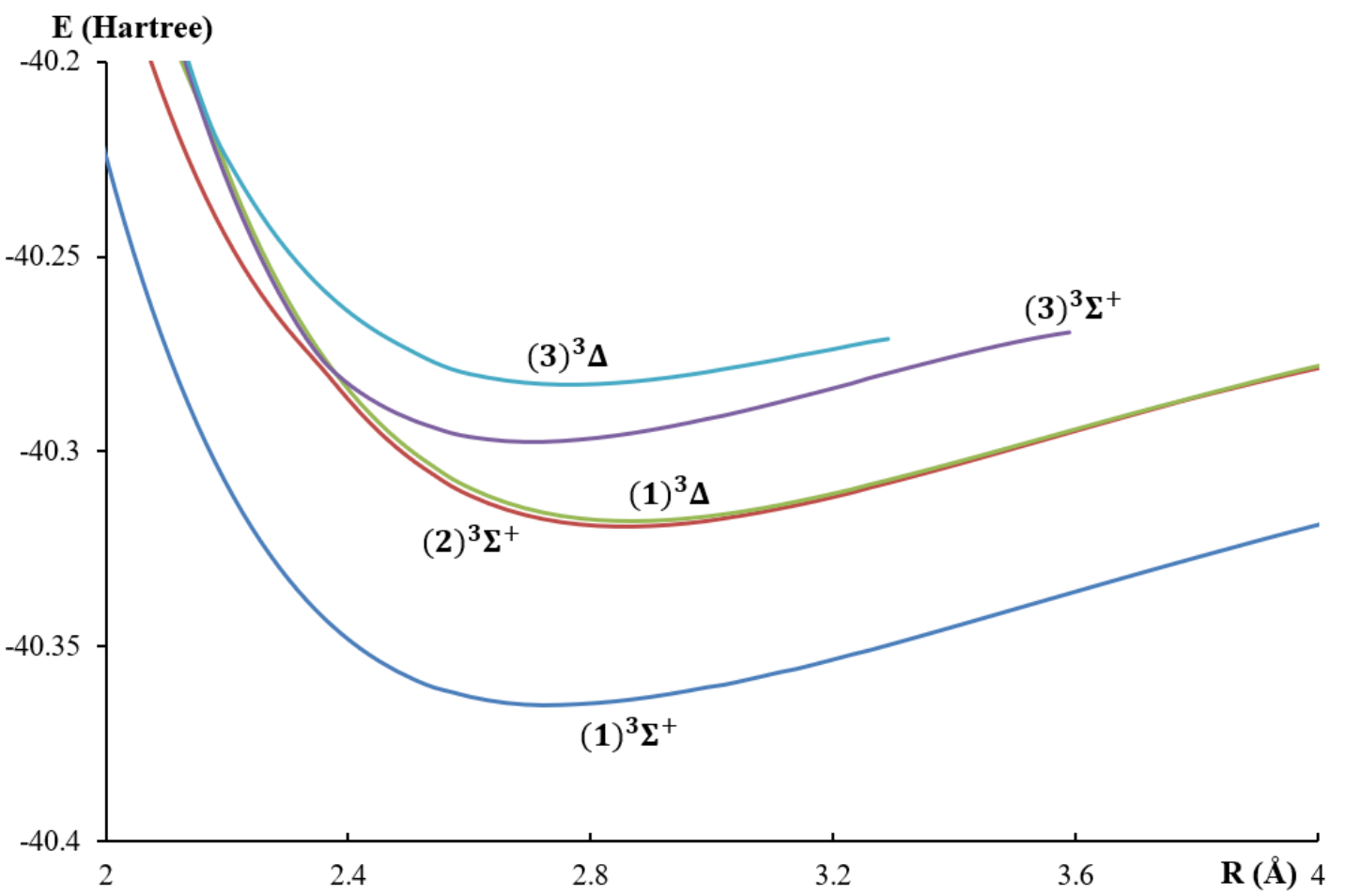

Figure 3. PECs of the triplet $\Sigma^{+}$and some triplet $\Delta$ electronic states of $\mathrm{SrS}$ 


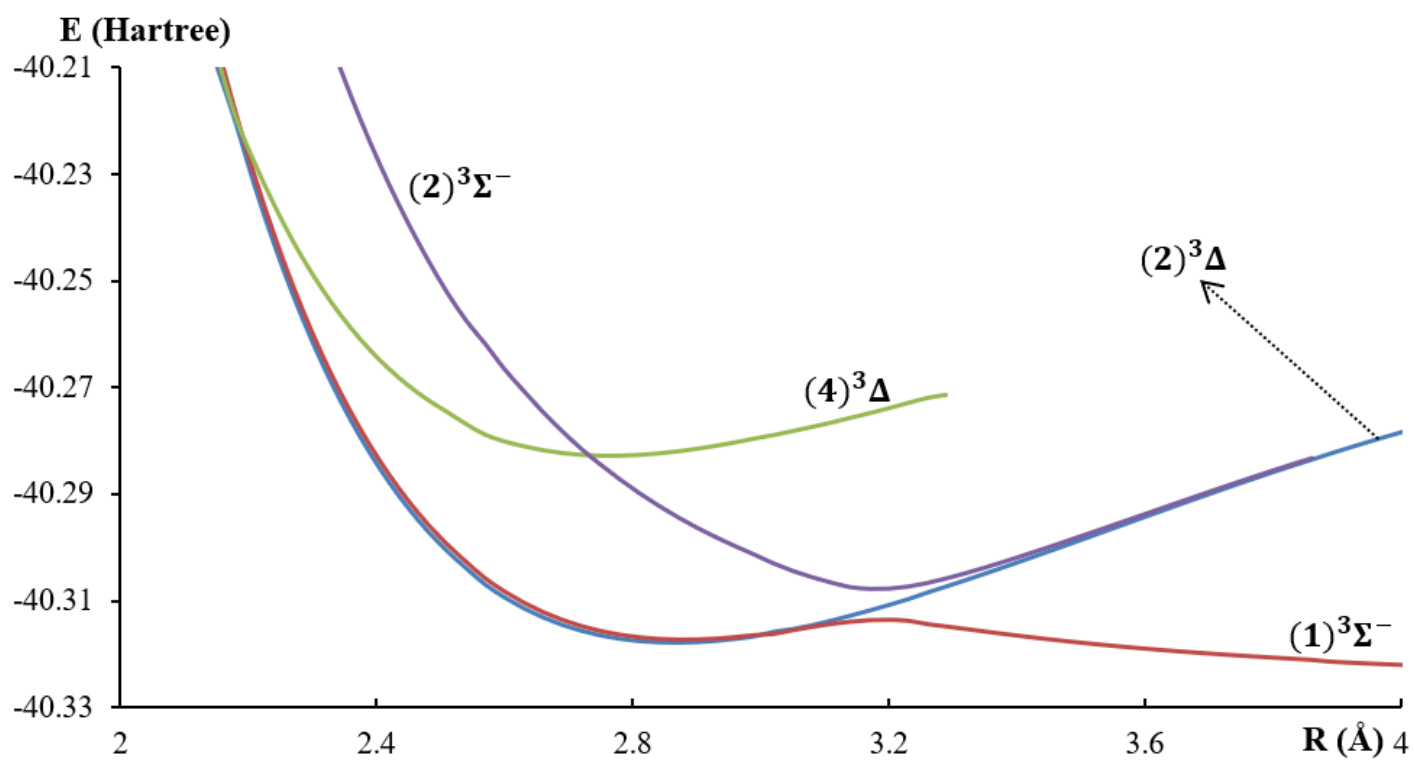

Figure 4. PECs of some triplet $\Delta$ and $\Sigma^{-}$electronic states of $\operatorname{SrS}$

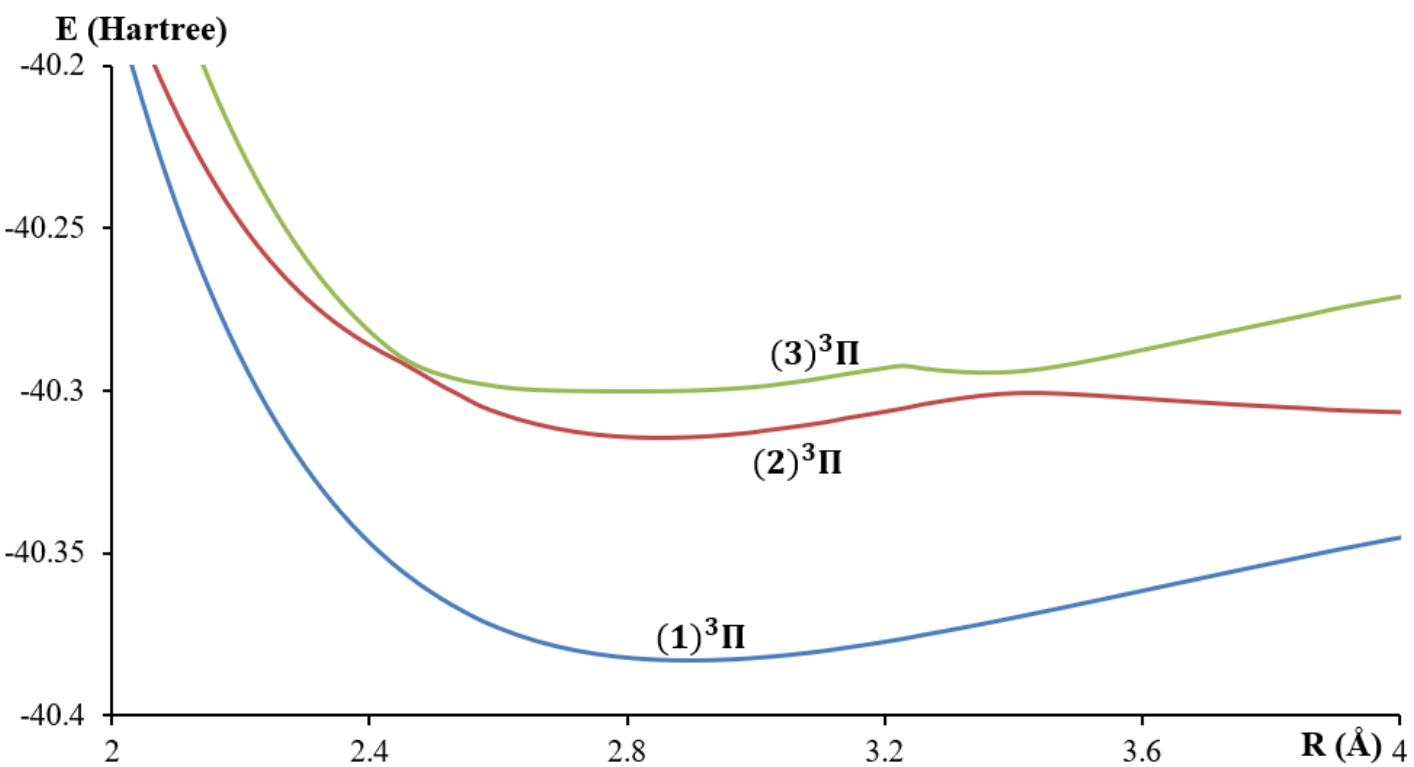

Figure 5. PECs of the triplet $\Pi$ electronic states of SrS

By fitting the potential energy values into a polynomial in $\mathrm{R}$ around the internuclear distance at equilibrium, spectroscopic constants of SrS have been computed. The constants $T_{e}$ (the electronic energy with respect to the ground state), $\omega_{\mathrm{e}}$ (the harmonic vibrational frequency), $\mathrm{R}_{\mathrm{e}}$ (the equilibrium internuclear distance), $\mathrm{B}_{\mathrm{e}}$ (the rotational constant) and $\mathrm{D}_{\mathrm{e}}$ (the equilibrium dissociation energy) have been obtained for 19 singlet and triplet $\mathrm{SrS}$ electronic states (Table 1). The spectroscopic constants of few other electronic states have not been calculated since the minima of their potential energy curves exist near locations of crossing or avoided-crossing between two states.

In order to study the effect of decreasing the core orbitals of the SrS molecule during the MRCI calculations, another MRDSCI computational trial has been applied to 2 states of $\mathrm{SrS}$ (using the same $\mathrm{Sr}$ and $\mathrm{S}$ basis sets mentioned earlier) by removing 1 of the closed-shell $s$ orbitals from the core orbitals and the corresponding spectroscopic constants have been calculated (Table $\left.1 /{ }^{b}\right)$. One can notice that this trial has lead to promising results in comparison to previous experimental studies. 
Table 1. Calculated spectroscopic constants for the singlet and triplet electronic states of the SrS molecule.

\begin{tabular}{|c|c|c|c|c|c|}
\hline State & $\mathrm{T}_{\mathrm{e}}\left(\mathrm{cm}^{-1}\right)$ & $\mathrm{r}_{\mathrm{e}}(\AA)$ & $\omega_{\mathrm{e}}\left(\mathrm{cm}^{-1}\right)$ & $\mathrm{B}_{\mathrm{e}}\left(\mathrm{cm}^{-1}\right)$ & $10^{8} \mathrm{D}_{\mathrm{e}}\left(\mathrm{cm}^{-1}\right)$ \\
\hline \multirow[t]{12}{*}{$\mathrm{X}^{1} \Sigma^{+}$} & $0^{\mathrm{a}}$ & $2.607^{\mathrm{a}}$ & $269.3049^{a}$ & $0.105544^{\mathrm{a}}$ & $6.54^{\mathrm{a}}$ \\
\hline & $0^{\mathrm{b}}$ & $2.589^{\mathrm{b}}$ & $312.0721^{b}$ & $0.107188^{b}$ & $5.01^{\mathrm{b}}$ \\
\hline & $0^{\mathrm{c}}$ & $2.440^{\mathrm{c}}$ & $388.38^{\mathrm{c}}$ & $0.12072^{\mathrm{c}}$ & $4.75^{\mathrm{c}}$ \\
\hline & $0^{\mathrm{d}, 1}$ & $2.484^{\mathrm{d}, 1}$ & $390^{\mathrm{d}, 1}$ & & \\
\hline & $0^{\mathrm{d}, 2}$ & $2.507^{\mathrm{d}, 2}$ & $363^{\mathrm{d}, 2}$ & & \\
\hline & $0^{\mathrm{d}, 3}$ & $2.458^{\mathrm{d}, 3}$ & $377^{\mathrm{d}, 3}$ & & \\
\hline & $0^{\mathrm{e}}$ & $2.439^{\mathrm{e}}$ & $388.2643^{\mathrm{e}}$ & $0.120803^{\mathrm{e}}$ & $4.87^{\mathrm{e}}$ \\
\hline & $0^{\mathrm{f}}$ & $2.441^{\mathrm{f}}$ & & $0.120797^{\mathrm{f}}$ & $4.67^{\mathrm{f}}$ \\
\hline & $0^{\mathrm{g}, 1}$ & $2.439^{\mathrm{g}, 1}$ & & $0.120793^{\mathrm{g}, 1}$ & $4.67^{\mathrm{g}, 1}$ \\
\hline & $0^{\mathrm{g}, 2}$ & $2.439^{\mathrm{g}, 2}$ & & $0.121162^{\mathrm{g}, 2}$ & $4.70^{\mathrm{g}, 2}$ \\
\hline & $0^{\mathrm{g}, 3}$ & $2.439^{\mathrm{g}, 3}$ & & $0.121541^{\mathrm{g}, 3}$ & $4.73^{\mathrm{g}, 3}$ \\
\hline & $0^{\mathrm{g}, 4}$ & $2.439^{\mathrm{g}, 4}$ & & $0.115589^{\mathrm{g}, 4}$ & $4.28^{\mathrm{g}, 4}$ \\
\hline \multirow[t]{2}{*}{$(1)^{1} \Pi$} & $3522.03^{a}$ & $2.891^{\mathrm{a}}$ & $231.7985^{\mathrm{a}}$ & $0.085891^{\mathrm{a}}$ & $4.71^{\mathrm{a}}$ \\
\hline & $7179^{\mathrm{d}, 1}$ & $2.751^{\mathrm{d}, 1}$ & $273^{\mathrm{d}, 1}$ & & \\
\hline \multirow[t]{6}{*}{$(1)^{3} \Pi$} & $6548.01^{\mathrm{a}}$ & $2.897^{\mathrm{a}}$ & $227.2335^{\mathrm{a}}$ & $0.085535^{\mathrm{a}}$ & $4.84^{\mathrm{a}}$ \\
\hline & $9881^{\mathrm{d}, 1}$ & $2.788^{\mathrm{d}, 1}$ & $273^{\mathrm{d}, 1}$ & & \\
\hline & $5503^{\mathrm{d}, 2}$ & $2.807^{\mathrm{d}, 2}$ & $262^{\mathrm{d}, 2}$ & & \\
\hline & $5823^{\mathrm{d}, 3}$ & $2.749^{\mathrm{d}, 3}$ & $270^{\mathrm{d}, 3}$ & & \\
\hline & $6550^{\mathrm{d}, 4}$ & $2.808^{\mathrm{d}, 4}$ & $258^{\mathrm{d}, 4}$ & & \\
\hline & $6870^{\mathrm{d}, 5}$ & $2.748^{\mathrm{d}, 5}$ & $271^{\mathrm{d}, 5}$ & & \\
\hline$(1)^{3} \Sigma^{+}$ & $10494.48^{\mathrm{a}}$ & $2.733^{\mathrm{a}}$ & $256.8097^{\mathrm{a}}$ & $0.096122^{\mathrm{a}}$ & $5.37^{\mathrm{a}}$ \\
\hline \multirow[t]{3}{*}{$(2)^{1} \Sigma^{+}$} & $11937.50^{\mathrm{a}}$ & $2.613^{\mathrm{a}}$ & $304.3698^{\mathrm{a}}$ & $0.105109^{\mathrm{a}}$ & $5.01^{\mathrm{a}}$ \\
\hline & $11753.24^{b}$ & $2.613^{b}$ & $305.7439^{b}$ & $0.105091^{b}$ & $5.04^{\mathrm{b}}$ \\
\hline & $13932.70^{\mathrm{e}}$ & $2.511^{\mathrm{e}}$ & $339.1454^{\mathrm{e}}$ & $0.113989^{\mathrm{e}}$ & $6.16^{\mathrm{e}}$ \\
\hline$(1)^{1} \Delta$ & $17262.06^{\mathrm{a}}$ & $2.871^{\mathrm{a}}$ & $234.3688^{\mathrm{a}}$ & $0.087133^{\mathrm{a}}$ & $4.81^{\mathrm{a}}$ \\
\hline$(2)^{1} \Delta$ & $17262.38^{\mathrm{a}}$ & $2.870^{\mathrm{a}}$ & $234.3205^{\mathrm{a}}$ & $0.087134^{\mathrm{a}}$ & $4.82^{\mathrm{a}}$ \\
\hline$(3)^{1} \Sigma^{+}$ & $17395.79^{\mathrm{a}}$ & $2.857^{\mathrm{a}}$ & $244.7969^{\mathrm{a}}$ & $0.087986^{\mathrm{a}}$ & $4.54^{\mathrm{a}}$ \\
\hline$(1)^{1} \Sigma^{-}$ & $17540.41^{\mathrm{a}}$ & $2.878^{\mathrm{a}}$ & $232.2611^{\mathrm{a}}$ & $0.086709^{a}$ & $4.83^{\mathrm{a}}$ \\
\hline$(2)^{1} \Pi$ & $18444.97^{\mathrm{a}}$ & $2.873^{\mathrm{a}}$ & $234.6076^{\mathrm{a}}$ & $0.086972^{\mathrm{a}}$ & $4.78^{\mathrm{a}}$ \\
\hline$(2)^{3} \Sigma^{+}$ & $20609.10^{\mathrm{a}}$ & $2.858^{\mathrm{a}}$ & $238.2755^{\mathrm{a}}$ & $0.087915^{\mathrm{a}}$ & $4.79^{\mathrm{a}}$ \\
\hline$(1)^{3} \Sigma^{-}$ & $20862.41^{\mathrm{a}}$ & $2.868^{\mathrm{a}}$ & $236.8683^{\mathrm{a}}$ & $0.087246^{\mathrm{a}}$ & $4.75^{\mathrm{a}}$ \\
\hline$(1)^{3} \Delta$ & $20862.98^{\mathrm{a}}$ & $2.867^{\mathrm{a}}$ & $236.7714^{\mathrm{a}}$ & $0.087358^{\mathrm{a}}$ & $4.75^{\mathrm{a}}$ \\
\hline$(2)^{3} \Delta$ & $21031.22^{\mathrm{a}}$ & $2.879^{\mathrm{a}}$ & $224.0832^{\mathrm{a}}$ & $0.086647^{\mathrm{a}}$ & $5.13^{\mathrm{a}}$ \\
\hline$(2)^{3} \Pi$ & $21635.23^{\mathrm{a}}$ & $2.850^{\mathrm{a}}$ & $249.6852^{\mathrm{a}}$ & $0.088391^{\mathrm{a}}$ & $4.40^{\mathrm{a}}$ \\
\hline$(4)^{1} \Sigma^{+}$ & $22386.03^{\mathrm{a}}$ & $2.736^{\mathrm{a}}$ & $260.7516^{\mathrm{a}}$ & $0.095836^{\mathrm{a}}$ & $5.17^{\mathrm{a}}$ \\
\hline$(3)^{1} \Delta$ & $25241.23^{\mathrm{a}}$ & $2.756^{\mathrm{a}}$ & $236.7732^{\mathrm{a}}$ & $0.094536^{\mathrm{a}}$ & $6.02^{\mathrm{a}}$ \\
\hline$(3)^{3} \Sigma^{+}$ & $25323.85^{\mathrm{a}}$ & $2.700^{\mathrm{a}}$ & $266.1296^{a}$ & $0.098487^{a}$ & $5.36^{\mathrm{a}}$ \\
\hline$(3)^{3} \Delta$ & $28562.08^{\mathrm{a}}$ & $2.767^{\mathrm{a}}$ & $208.6114^{\mathrm{a}}$ & $0.093624^{\mathrm{a}}$ & $7.76^{\mathrm{a}}$ \\
\hline
\end{tabular}

${ }^{\text {aPresent }}$ work with all core orbitals during the CASSCF/MRDSCI calculation.

${ }^{b}$ Present work by decreasing the core orbitals by 1 during the CASSCF/MRDSCI calculation (for 2 states only).

${ }^{\mathrm{c}}$ Experimental work by M. Marcano and R. F. Barrow (Marcano \& Barrow, 1970).

${ }^{\mathrm{d}}$ Theoretical work by Partridge et al. using 5 methods (d1: CASSCF, d2: CCI, d3: CCI (4s4p), d4: MRCI, d5: MRCI+Core) (Partridge, Langhoff, \& Bauschlicher, 1988).

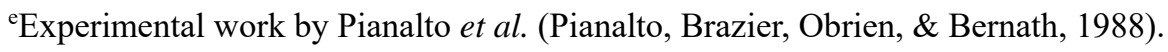

${ }^{\mathrm{f}}$ Experimental work by Halfen et al. (Halfen, Apponi, Thompsen, \& Ziurys, 2001).

${ }^{g}$ Experimental work by K. C. Etchison for 4 SrS isotopes $\left(\mathrm{g} 1:{ }^{88} \mathrm{Sr}^{32} \mathrm{~S}, \mathrm{~g} 2:{ }^{87} \mathrm{Sr}^{32} \mathrm{~S}, \mathrm{~g} 3{ }^{86} \mathrm{Sr}^{32} \mathrm{~S}, \mathrm{~g} 4:{ }^{88} \mathrm{Sr}^{34} \mathrm{~S}\right)$ (Etchison \& Cooke, 2010).

In Table 1, the obtained results are compared to the results of the experimental and theoretical studies found in earlier literature (Marcano \& Barrow, 1970) (Partridge, Langhoff, \& Bauschlicher, 1988) (Pianalto, Brazier, 
Obrien, \& Bernath, 1988) (Halfen, Apponi, Thompsen, \& Ziurys, 2001) (Etchison \& Cooke, 2010). The spectroscopic constants in our study are generally in good agreement with the previous theoretical and experimental work. For instance, it is noticeable that the constants calculated here are very close to the CCI, MRCI and MRCI+Core theoretical outcomes of Partridge et al. (Table $1 / \mathrm{d} 2, \mathrm{~d} 4$ and $\mathrm{d} 5$ ) (Partridge, Langhoff, \& Bauschlicher, 1988). As for the $T_{e}$ values of the states $(1)^{1} \Pi$ and $(1)^{3} \Pi$ resulting from the CASSCF method used by Partridge et al., they are remarkably higher than the results in the present study (Table $1 /{ }^{\mathrm{d} 1}$ ). This can be explained by the fact that the CASSCF method can be considered as a full CI computation in a restricted configurational space, which is sometimes problematic during the process of selecting configurations, whereas a multi-reference CI tends to result in more optimized calculations (Kohanoff, 2006).

Some sites of crossing and avoided-crossing between different electronic states of strontium mono-sulfide appear in the PECs (Fig. 1-5). For example, in Figure 1, each of the states (1) ${ }^{1} \Delta$ and $(2)^{1} \Delta$ avoided crossing with the state $(3)^{1} \Delta$ at $\mathrm{R}=2.18 \AA$ while the state $(3)^{1} \Sigma^{+}$avoided crossing with the state $(4)^{1} \Sigma^{+}$at $\mathrm{R}=2.3 \AA$. Figure 2 also shows avoided-crossing between states $(2)^{1} \Pi$ and $(3)^{1} \Pi$ at $R=2.48 \AA$ and crossing between states $(1)^{1} \Phi$ and $(3)^{1} \Pi$ at $R=2.84 \AA$ and $R=3.92 \AA$. Likewise, Figures $3-5$ indicate avoided-crossing between electronic states as follows: (2) ${ }^{3} \Sigma^{+}$with $(3)^{3} \Sigma^{+}$at $\mathrm{R}=2.36 \AA$, (1) ${ }^{3} \Delta$ with $(3)^{3} \Delta$ at $\mathrm{R}=2.18 \AA$, (2) ${ }^{3} \Delta$ with (4) ${ }^{3} \Delta$ at $\mathrm{R}=2.18 \AA$, $(1)^{3} \Sigma^{-}$with $(2)^{3} \Sigma^{-}$at $\mathrm{R}=3.2 \AA$, and $(2)^{3} \Pi$ with $(3)^{3} \Pi$ at $\mathrm{R}=2.48 \AA$ and $\mathrm{R}=3.38 \AA$. In Figures $3-5$, crossings of electronic states appear in the following manner: $(3)^{3} \Sigma^{+}$with $(1)^{3} \Delta$ at $\mathrm{R}=2.18 \AA$ and $\mathrm{R}=2.36 \AA$, (1) ${ }^{3} \Sigma^{-}$ with $(4)^{3} \Delta$ at $\mathrm{R}=2.18 \AA$, (2) ${ }^{3} \Sigma^{-}$with $(4)^{3} \Delta$ at $\mathrm{R}=2.72 \AA$, and $(1)^{3} \Sigma^{-}$with $(2)^{3} \Delta$ at $\mathrm{R}=2.18 \AA$ and $\mathrm{R}=3.02 \AA$.

\subsection{Permanent Dipole Moment Curves}

The permanent dipole moment curves (DMCs) have been obtained for the different electronic states of the molecule SrS (Fig. 6-10).

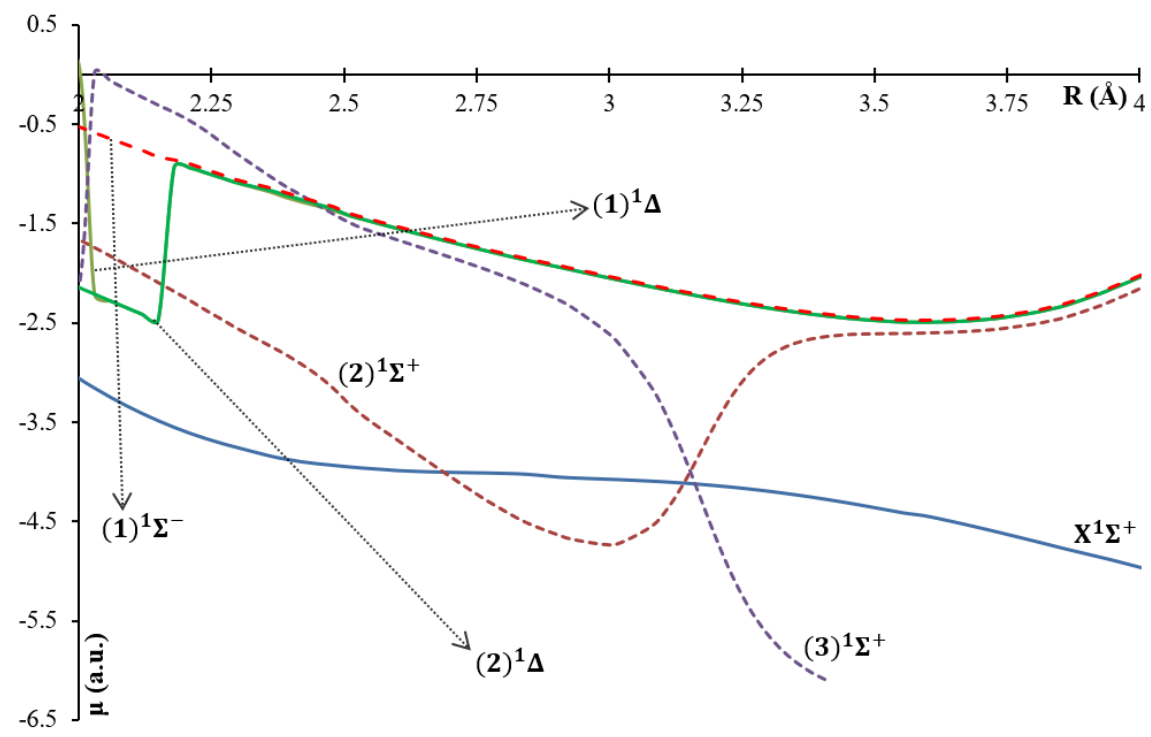

Figure 6. DMCs of the singlet $\Sigma$ and $\Delta$ electronic states of $\mathrm{SrS}$

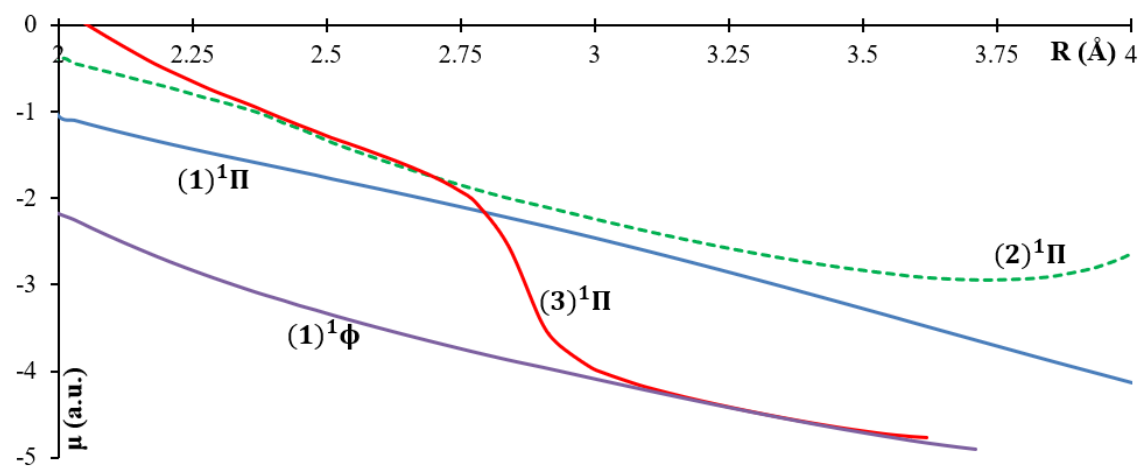

Figure 7. DMCs of the singlet $\Pi$ and $\Phi$ electronic states of $\mathrm{SrS}$ 


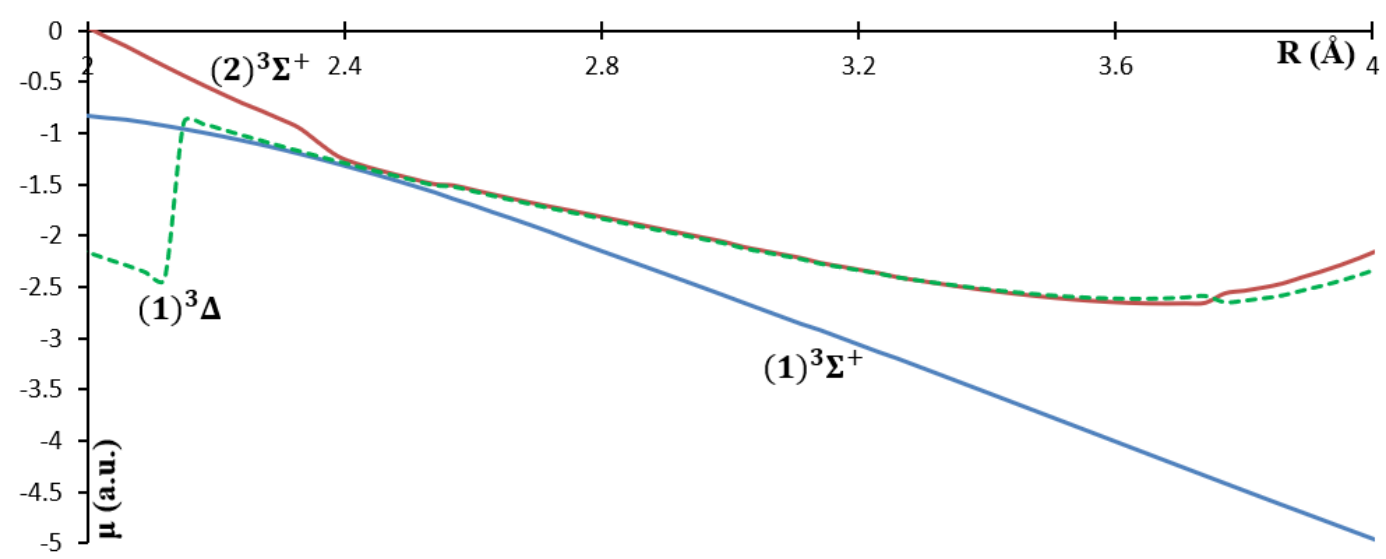

Figure 8. DMCs of some triplet $\Sigma^{+}$and $\Delta$ electronic states of $\mathrm{SrS}$

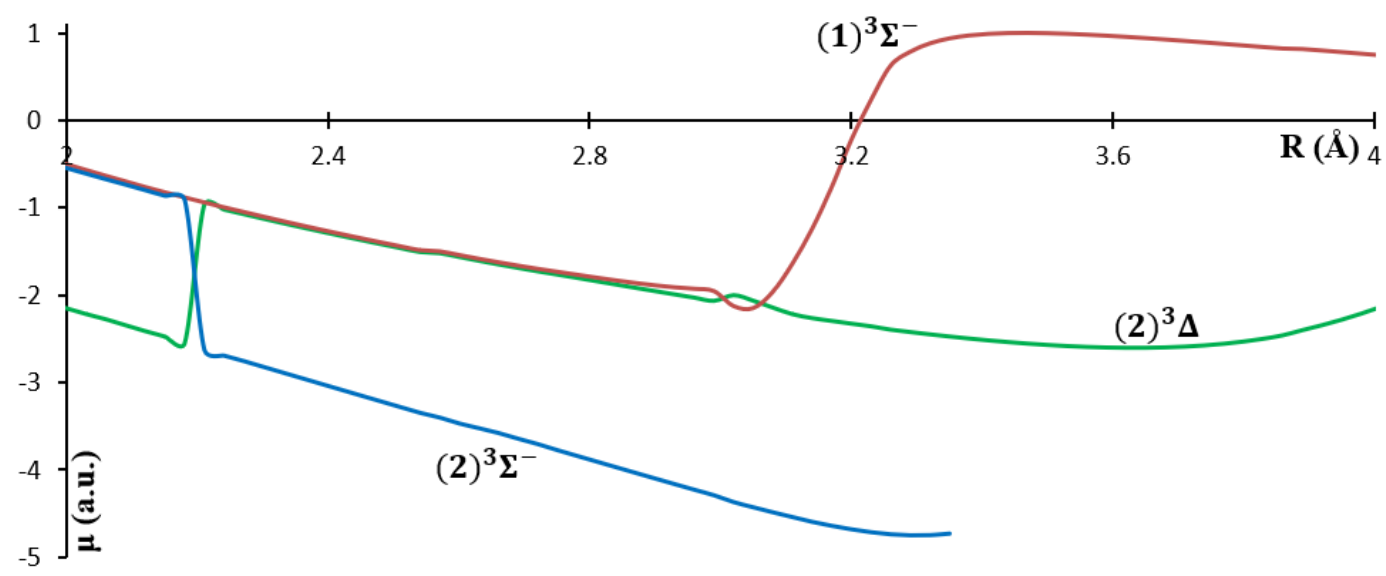

Figure 9. DMCs of some triplet $\Delta$ and $\Sigma^{-}$electronic states of $\mathrm{SrS}$

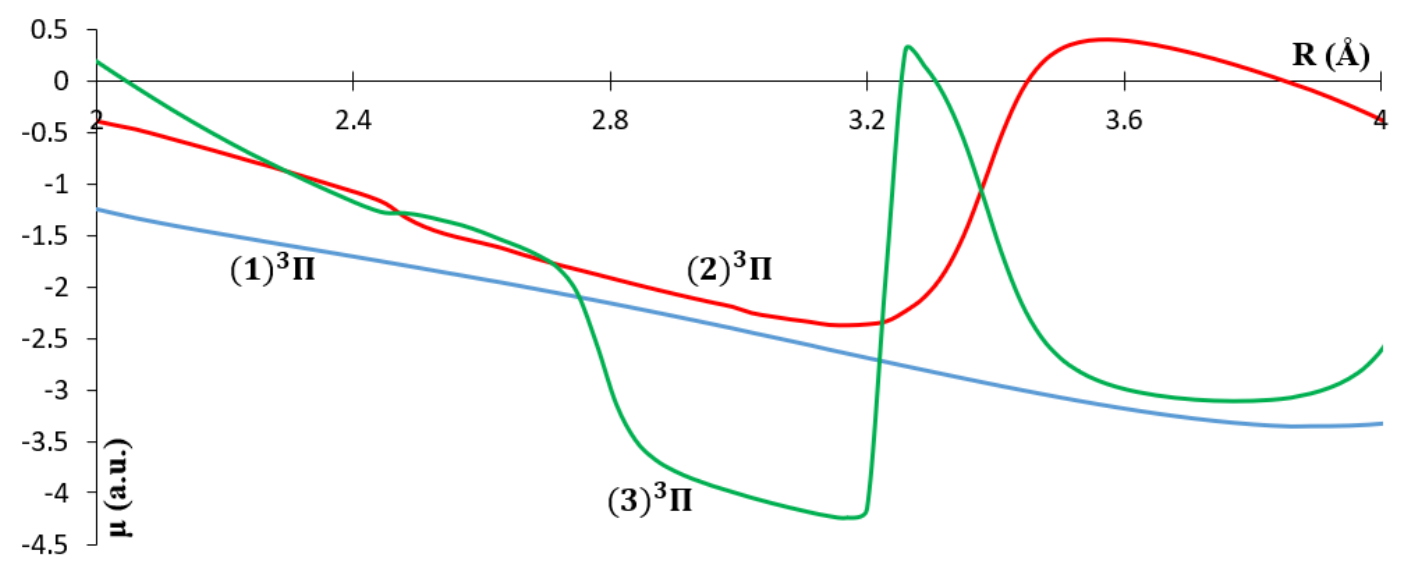

Figure 10. DMCs of the triplet $\Pi$ electronic states of SrS

The permanent dipole moment $\mu_{\mathrm{e}}$ is considered as one of the dependable physical properties (Steimle, 2000). It has been computed in this study by fixing the strontium atom ( $\mathrm{Sr}$ ) at the origin and by keeping the sulfur atom (S) free to move along the positive z-axis. Our calculations have been performed with the aid of the MOLPRO program (Werner, Knowles, Knizia, Manby, \& Schütz, 2011). Usually, a reverse in the polarity of the atoms is reflected by a sharp change in the directions of the permanent DMCs. This occurs at positions of the internuclear distance (R) where avoided-crossing between electronic states exists in the potential energy curves (PECs). In the present work, one can notice that such sharp changes in the directions of our permanent dipole moment curves match very well with the R locations of avoided-crossing in PECs of SrS. This is an indication of the 
good accuracy of the results presented in this study.

\section{Conclusion}

In the present work, 24 singlet and triplet electronic states of the strotium mono-sulfide molecule have been investigated using the $a b$ initio computational method. The CASSCF/MRCI method applied to the SrS molecule, in the ${ }^{2 s+1} \Lambda^{ \pm}$representation, resulted in the calculation of the potential energy curves, the permanent dipole moment $\left(\mu_{\mathrm{e}}\right)$ curves, the electronic energy with respect to the ground state $\left(T_{e}\right)$, the harmonic frequency $\left(\omega_{e}\right)$, the rotational constant $\left(B_{e}\right)$, the internuclear distance $\left(R_{e}\right)$ and the dissociation energy $\left(D_{e}\right)$. The current results generally show good agreement with the results available in literature. To the best of our knowledge, 20 new electronic states of $\mathrm{SrS}$ have been examined in this work for the first time. It should be noted that the new study, presented here, may aid in promising experimental investigations on the strontium mono-sulfide molecule in the future.

\section{References}

Allouche, A. (2011). Gabedit-A graphical user interface for computational chemistry softwares. Journal of Computational Chemistry, 32(1), 174-182. https://doi.org/10.1002/jcc.21600

Bergner, A., Dolg, M., Kuechle, W., Stoll, H., \& Preuss, H. (1993). Ab initio energy-adjusted pseudopotentials for elements of groups 13-17. Molecular Physics, 80(6), 1431-1441. https://doi.org/10.1080/00268979300103121

Bradley, D. C. (1989). Metal alkoxides as precursors for electronic and ceramic materials. Chemical Reviews, 89(6), 1317-1322. https://doi.org/10.1021/cr00096a004

Etchison, K. C., \& Cooke, S. A. (2010). The pure rotational spectra of diatomics and halogen-addition benzene measured by microwave and radio frequency spectrometers (Unpublished master's thesis). UNIVERSITY OF NORTH TEXAS.

Halfen, D. T., Apponi, A. J., Thompsen, J. M., \& Ziurys, L. M. (2001). The pure rotational spectra of SrSH ( $\left.\tilde{X}^{2} A^{\prime}\right)$ and $\operatorname{SrS}\left(\mathrm{X}^{1} \Sigma^{+}\right)$: Further studies in alkaline-earth bonding. The Journal of Chemical Physics, 115(24), 11131-11138. https://doi.org/10.1063/1.1419060

Holm, R. H., Kennepohl, P., \& Solomon, E. I. (1996). Structural and Functional Aspects of Metal Sites in Biology. Chemical Reviews, 96(7), 2239-2314. https://doi.org/10.1021/cr9500390

Huber, K. P., \& Herzberg, G. (1979). Constants of diatomic molecules. Molecular Spectra and Molecular Structure, 8-689. https://doi.org/10.1007/978-1-4757-0961-2_2

Janczyk, A., \& Ziurys, L. (2006). Sub-millimeter spectroscopy of BaS $\left(\mathrm{X}^{1} \Sigma^{+}\right)$. Journal of Molecular Spectroscopy, 236(1), 11-15. https://doi.org/10.1016/j.jms.2005.11.011

Kaupp, M., Schleyer, P. v. R., Stoll, H., \& Preuss, H. (1991). Pseudopotential approaches to Ca, Sr, and Ba hydrides. Why are some alkaline earth MX2 compounds bent? The Journal of Chemical Physics, 94(2), 1360-1366. https://doi.org/10.1063/1.459993

Kohanoff, J. (2006). Electronic structure calculations for solids and molecules: Theory and computational methods. Cambridge: Cambridge Univ. Press.

Marcano, M., \& Barrow, R. F. (1970). Rotational analysis of a ${ }^{1} \Sigma^{+}-1 \Sigma^{+}$system of gaseous SrS. Transactions of the Faraday Society, 66, 1917. https://doi.org/10.1039/tf9706601917

Partridge, H., Langhoff, S. R., \& Bauschlicher, C. W. (1988). Theoretical study of the alkali and alkaline-earth monosulfides. The Journal of Chemical Physics, 88(10), 6431-6437. https://doi.org/10.1063/1.454429

Pianalto, F., Brazier, C., Obrien, L., \& Bernath, P. (1988). Rotational analysis of the $\mathrm{A}^{1} \Sigma^{+}-\mathrm{X}^{1} \Sigma^{+}$transition of SrS. Journal of Molecular Spectroscopy, 132(1), 80-88. https://doi.org/10.1016/0022-2852(88)90060-4

Steimle, T. C. (2000). Permanent electric dipole moments of metal containing molecules. International Reviews in Physical Chemistry, 19(3), 455-477. https://doi.org/10.1080/01442350050034199

Takano, S., Yamamoto, S., \& Saito, S. (1989). Millimeter wave spectra of MgS and CaS. Chemical Physics Letters, 159(5-6), 563-566. https://doi.org/10.1016/0009-2614(89)87533-5

Werner, H., Knowles, P. J., Knizia, G., Manby, F. R., \& Schütz, M. (2011). Molpro: A general-purpose quantum chemistry program package. Wiley Interdisciplinary Reviews: Computational Molecular Science, 2(2), 242-253. https://doi.org/10.1002/wcms.82 


\section{Copyrights}

Copyright for this article is retained by the author(s), with first publication rights granted to the journal.

This is an open-access article distributed under the terms and conditions of the Creative Commons Attribution license (http://creativecommons.org/licenses/by/4.0/). 